\title{
Probióticos em avicultura
}

\author{
Probiotics in aviculture
}

\author{
João Rodrigo Gil de los Santos ${ }^{1}$ Carlos Gil-Turnes ${ }^{2}$
}

\section{- REVISÃO BIBLIOGRÁFICA -}

RESUMO

Durante os últimos anos, o incremento de toxinfecções alimentares em humanos pela ingestão de produtos avícolas contaminados com bactérias, sugeriu que produtos oriundos de aves portadoras dessas bactérias podem veiculá-las ao consumidor, provocando doenças entéricas em humanos. Essas observações e a restrição, por parte do mercado consumidor, ao uso de antimicrobianos na produção animal, aumentaram o interesse mundial pelos probióticos $e$, conseqüentemente, o número de pesquisas realizadas. Esta revisão mostra os avanços e a situação em que se encontram os probióticos em relação à indústria avícola.

Palavras-chave: probióticos, avicultura, patógenos entéricos, frangos, antimicrobianos.

\section{ABSTRACT}

During the latest years human enteric diseases were associated to the ingestion of poultry products contaminated by bacteria, suggesting that foods produced with meat from contaminated animals could transport bacteria to humans. These observations, and the restrictions imposed by the market to the use of antimicrobials in meat production, increased the interest on probiotics all around the world. This review shows the advances and the current situation of probiotics in the poultry industry.

Key words: probiotics, poultry, enteric pathogens, broilers, antimicrobials.

\section{INTRODUÇÃO}

As doenças entéricas tornaram-se um dos maiores desafios para a avicultura industrial mundial nos últimos anos devido à perda de produtividade, ao aumento de mortalidade e à contaminação de produtos de origem avícola para o consumo humano, que elas determinam. Com frequiência crescente, produtos avícolas têm sido relacionados com toxinfecções alimentares em humanos em vários países, sugerindo que produtos elaborados com carne de aves portadoras de bactérias possam ser fontes de infecção.

Entre a profusa informação veiculada, pode citar-se, a modo de exemplo, que, na Coréia isolou-se Salmonella spp. de 25,9\% das amostras de carne de frango, sendo $S$. enteritidis um dos sorotipos predominantes. Além disso, todas as salmonelas isoladas apresentaram resistência múltipla a antibióticos, dentre eles a penicilina e vancomicina, sendo uma amostra de $\boldsymbol{S}$. enteritidis resistente a doze antibióticos (CHANG, 2000). Na Espanha, comprovouse que o isolamento de $S$. enteritidis aumentou $126 \%$ em dois anos, sendo o sorotipo predominante em ovos e carne de aves (GIL-SETAS et al., 2002). Em outro trabalho, também na Espanha, foi isolada Salmonella

${ }^{1}$ Médico Veterinário, MSc, Programa de Pós-graduação em Biotecnologia Agrícola, Centro de Biotecnologia, Universidade Federal de Pelotas, Brasil.

${ }^{2}$ Médico Veterinário, MSc, DSc, Professor Titular, Faculdade de Veterinária, Centro de Biotecnologia, Universidade Federal de Pelotas, Campus Universitário, s/n, CP. 354, 96010-900, Brasil. E-mail: gil@ufpel.tche.br 
em 35,8\% de 198 amostras de carne de frango provenientes de mercados e supermercados localizados em nove províncias de Castilla-León, dos quais 47,9\% eram S. enteritidis (DOMINGUEZ et al., 2002). Em Portugal, 60\% das amostras de produtos de origem avícola, disponíveis para consumidores, obtidos em açougues e mercados da cidade do Porto estavam contaminadas, sendo as $\boldsymbol{S}$. enteritidis e $\boldsymbol{S}$. hadar os sorotipos predominantes (ANTUNES et al., 2003).

Campylobacter é outro agente de infecções alimentares humanas relacionado com a ingestão de produtos avícolas. Na Itália, foi detectado Campylobacter spp. em 53,9\% de amostras de carne bovina, $63,5 \%$ de suínos e $82,9 \%$ de frangos, com vários isolados apresentando resistência múltipla a antibacterianos (PEZZOTTI et al., 2003). Na Dinamarca, esta bactéria foi isolada de $100 \%$ das amostras de frangos orgânicos, de $36,7 \%$ de animais de granjas convencionais e de $49,2 \%$ de animais de galpões (ANÔNIMO, 2001). Na França, detectou-se Campylobacter em 71,2\% das amostras de excreta coletadas em dois aviários, e em $75 \%$ das amostras de comidas presentes em supermercados (DENIS et al., 2001). FALLON et al. (2003) verificaram, na Irlanda, que $35,9 \%$ dos isolamentos de $\boldsymbol{C}$. jejuni foram resistentes a ampicilina, 20,5\% a tetraciclina, $17,9 \%$ a ciprofloxacina, $10,2 \%$ a eritromicina e $2,5 \%$ a estreptomicina, sendo $30,7 \%$ resistentes a mais de um antibiótico.

Outras bactérias freqüentemente envolvidas em toxinfecções alimentares humanas são as integrantes do gênero Listeria. ANTUNES et al. (2002) encontraram Listeria em 100\% das amostras de carcaças de frangos de mercados da cidade do Porto, Portugal, sendo $41 \%$ L. monocytogenes, patógeno que causa doenças graves em humanos e animais.

No Brasil, há também vários registros sobre ocorrência de bactérias isoladas de aves ou seus produtos, potencialmente produtoras de toxinfecções alimentares em humanos. PERESI et al. (1998) isolaram S. enteritidis PT-4 de todas as amostras de alimentos e de $80,5 \%$ das coproculturas de pacientes de 23 surtos de salmonelose em humanos ocorridos entre 1993 e 1997 no Estado de São Paulo, sendo que, em 95,7\% dos surtos, a bactéria foi veiculada por alimentos contendo ovos crus ou semicrus. SANTOS et al. (2000) encontraram salmonelas em $32 \%$ das 150 carcaças de frango de quatro plantas de processamento, identificando 11 sorotipos diferentes, representando S. enteritidis $60,4 \%$ dos isolamentos. BAÚ et al. (2001) analisaram 124 amostras de produtos de frangos obtidos de supermercados de Pelotas, RS, recuperando
S. enteritidis de 8\%. HOFER et al. (2000) estudaram 3112 cepas de Listeria isoladas no Brasil entre 1971 e 1997, sendo 74,8\% delas recuperadas de alimentos.

A alta freqüência de bactérias potencialmente patogênicas para animais e humanos presentes em produtos de origem animal, assim como o aumento de sua resistência aos antimicrobianos utilizados como suplementos alimentares, levaram a questionar o uso indiscriminado de antimicrobianos como aditivos em rações animais, dando sustentação às recomendações do Comitê Swann, na Grã Bretanha, em 1969 (SWANN COMMITTEE, 1969) e culminando com a proibição do uso de antimicrobianos como promotores de crescimento em animais pela União Européia a partir de 2006 (COUNCIL OF THE EUROPEAN UNION, 2003). Várias organizações, tais como o Parlamento Europeu, Comissão Européia, Organização Mundial da Saúde e Organização Mundial de Saúde Animal (COUNCIL OF EUROPE, 2000), têm recomendado regulamentar o uso de antimicrobianos como aditivos alimentares.

O resultado da proibição de uso de antimicrobianos como aditivos de rações na Suécia em 1986, assim como a restrição parcial de seu uso na Dinamarca em 1995 e 1998, e a proibição de outros cinco aditivos pela União Européia em 1999, resultaram na diminuição da resistência de enterococcos a avoparcina, macrólidos e virginiamicina, demonstrando que o número de genes de resistência a antibióticos nessas bactérias diminuiu (CASEWELL et al., 2002).

Resulta difícil imaginar a produção animal, nos níveis atuais de tecnificação e produtividade, sem o auxilio de aditivos alimentares para a prevenção de doenças ou como promotores de crescimento. Entre as diferentes alternativas que vêm sendo estudadas, os probióticos aparecem como as mais promissoras (REVINGTON, 2002; PATTERSON \& BURKHOLDER, 2003).

\section{Probióticos}

O conceito de probiótico tem mudado através do tempo. Para FULLER (1989) e KAUR et al. (2002), eles são suplementos alimentares compostos de microrganismos vivos que beneficiam a saúde do hospedeiro através do equilíbrio da microbiota intestinal. SALMINEN et al. (1999) os definem como preparados de microrganismos, ou seus componentes, que têm um efeito benéfico sobre a saúde e o bem estar do hospedeiro. SCHREZENMEIR \& DE VRESE (2001) consideraram que o termo probiótico deveria ser usado para designar preparações ou produtos que contêm microrganismos viáveis definidos e em quantidade adequada que alteram a microbiota própria 
das mucosas por colonização de um sistema do hospedeiro, produzindo efeitos benéficos em sua saúde. Independentemente do conceito utilizado, os probióticos trazem benefícios à saúde do hospedeiro, não deixam resíduos nos produtos de origem animal e não favorecem resistência às drogas (NEPOMUCENO \& ANDREATTI, 2000), o que os faz candidatos preferenciais para substituir os antimicrobianos como aditivos alimentares.

Os probióticos se empregam para prevenir ou tratar diversas disfunções gastrintestinais, tais como a intolerância à lactose, constipação, hipersensibilidade alimentar e gastrenterite, ou relacionadas a elas, como alergias e dermatite atópica. Os microrganismos utilizados como probióticos devem possuir certas propriedades, algumas das quais estão especificadas na tabela 1 (SALMINEN et al., 1998 a e b).

Os probióticos vêm sendo utilizados há anos na alimentação humana, tanto com finalidade profilática como terapêutica. Embora existam vários estudos que mostram seus benefícios como aditivos na alimentação animal, ainda há uma certa resistência por parte do setor industrial avícola em sua utilização.

Probióticos e índices de produtividade

Vários aspectos da aplicação dos probióticos em frangos de corte vêm sendo pesquisados, entre eles, seus efeitos nos índices de produtividade. Alguns pesquisadores afirmaram que a adição de microrganismos na ração não incrementou a produção de carne em aves. PANDA et al. (2000) utilizaram o produto comercial Probiolac ${ }^{\circledR}$, que em concentração de $100 \mathrm{mg} \mathrm{kg}^{-1}$ provocou aumento do ganho de peso de frangos até as quatro primeiras semanas, mas não melhorou a conversão alimentar. Da mesma forma, BALEVI et al. (2001) constataram que o Protexin ${ }^{\circledR}$, um produto comercial que contêm bactérias de quatro gêneros e fungos de dois, não alterou o consumo de ração nem a conversão alimentar, observação corroborada por LODDI et al. (2000), que verificaram que o probiótico não afetou os índices de ganho de peso nem a eficiência alimentar. ESTRADA et al. (2001) constataram que a administração de Bifidobacterium bifidum não provocou efeitos significativos no crescimento animal. REYES et al. (2000) obtiveram resultados similares com bactérias ácido láticas (LAB) ou láticas, entanto ZULKIFLI et al. (2000) atribuíram o aumento no consumo de ração e a diminuição da eficiência alimentar de frangos de corte à administração de Lactobacillus.

Em contraposição, várias pesquisas realizadas nos últimos anos mostraram resultados extremamente promissores pela adição de probióticos na dieta de frangos de corte. A administração de Bacillus cereus var. toyoii (CUEVAS et al., 2000) e Bacillus subtilis (SANTOSO et al., 1995; FRITTS et al., 2000) na ração, aumentou o ganho de peso e melhorou a conversão alimentar de frangos de corte. Já o B. coagulans teve o mesmo efeito que a virginiamicina como promotor de crescimento (CAVAZZONI et al., 1998). Bactérias do gênero Lactobacillus, adicionadas à ração, aumentaram o ganho de peso e melhoraram a conversão alimentar dos animais suplementados (JIN et al., 1998a; JIN et al., 1998b; KALAVATHY et al., 2003). Também foi comprovado o aumento do ganho de peso em animais suplementados com $\boldsymbol{L}$. agilitis JCM 1048 e L. salivarus subsp. salicinius JCM 1230 (LAN et al., 2003), e $\boldsymbol{L}$. acidophilus I 26 (JIN et al., 1998a), que também melhorou a conversão alimentar. Da mesma forma, MORENO et al. (2002) comprovaram os efeitos positivos de probióticos de Lactobacillus sobre a digestibilidade, ganho de peso e níveis de colesterol em frangos de corte, e OZCAN et al. (2003)

Tabela 1 - Propriedades dos microrganismos utilizados em probióticos.

\begin{tabular}{|c|c|}
\hline Características & Propriedades funcionais \\
\hline Estabilidade quando expostos à ação de ácidos e dos sais biliares & $\begin{array}{l}\text { Sobrevivência no intestino, mantendo a propriedade de adesão e outras } \\
\text { qualidades. }\end{array}$ \\
\hline Aderência aos enterócitos e muco intestinal & Imunomodulação e exclusão competitiva de patógenos \\
\hline Exclusão competitiva e colonização do trato intestinal & $\begin{array}{c}\text { Multiplicação no trato intestinal, exclusão competitiva de patógenos, } \\
\text { estímulo à microflora benéfica. }\end{array}$ \\
\hline Produção de substâncias antimicrobianas & Inativação de patógenos no intestino \\
\hline Antagonismo das bactérias patogênicas & $\begin{array}{c}\text { Exclusão do patógeno, prevenção da adesão do patógeno ao hospedeiro, } \\
\text { normalização da flora intestinal. }\end{array}$ \\
\hline Seguros para utilização & Identificação e caracterização do microrganismo utilizado \\
\hline Os efeitos devem ser clinicamente validados e documentados & Dosagem mínima efetiva capaz de promover uma resposta \\
\hline
\end{tabular}

Adaptado de SALMINEN et al. (1998a) e SALMINEN et al. (1998b). 
comprovaram melhora na eficiência alimentar e aumento no peso da carcaça de frangos suplementados com Enterococcus faecium Cernelle 68.

GIL de los SANTOS (2004) constatou que frangos de corte infectados com Salmonella enteritidis suplementados com Saccharomyces boulardii apresentaram eficiência alimentar $10 \%$ superior, e os suplementados com Bacillus cereus var. toyoii, $12 \%$ superior aos controles, e que seus pesos vivos aos 47 dias de idade eram $8 \%$ e $14 \%$ maiores que os controles, respectivamente.

\section{Probióticos, translocação e imunidade}

Outro aspecto de interesse crescente é o estudo do efeito dos probióticos na translocação (passagem de microrganismos através de mucosas) de patógenos, e no sistema imune do hospedeiro, cujos processos ainda não são adequadamente conhecidos. Tem sido relatado que alguns probióticos afetam a translocação bacteriana a partir do intestino, o que seria de grande importância para evitar as infecções de origem entérica, entre as quais as salmoneloses têm destacada importância.

Ainda que produtos comerciais à base de bactérias liofilizadas utilizados no processo de produção de carne avícola, tais como Protexin ${ }^{\circledR}$ (BALEVI et al., 2001) e Aviguard ${ }^{\circledR}$ não provocaram alterações na resposta imune, este último impediu a infecção por $\boldsymbol{S}$. typhimurium e $\boldsymbol{S}$. enteritidis (NAKAMURA et al., 2002). Da mesma forma, Broilact $^{\circledR}$ impediu ou reduziu a colonização de Campylobacter jejuni no ceco (HAKKINEN \& SCHNEITZ, 1999). Por sua vez, LINE et al. (1997) comprovaram que a levedura Saccharomyces boulardii reduziu a colonização de Salmonella em aves submetidas a estresse e, em trabalho posterior, que o probiótico reduziu a colonização de Salmonella, mas não de Campylobacter (LINE et al., 1998). Probióticos de Lactobacillus inibiram a infecção por $\boldsymbol{S}$. enteritidis em frangos (PASCUAL et al., 1999) e promoveram aumento na produção de anticorpos (ZULKIFLI et al., 2000). Também aumentaram a população de linfócitos intraepiteliais no intestino e promoveram a expressão de linfócitos $\mathrm{CD}_{3}, \mathrm{CD}_{4}$ e $\mathrm{CD}_{8}$, demonstrando que o estímulo da imunidade da mucosa intestinal pelo probiótico, previamente a uma infecção por Eimeria acervulina, podia proteger contra esse patógeno (DALLOUL et al., 2003). MATTAR et al. (2002) sugeriram que o efeito inibidor da translocação bacteriana exercido por Lactobacillus casei GG in vivo e in vitro, poderia estar relacionado com a regulação do gene MUC-
2, que promove a expressão de mucina pelos enterócitos.

O efeito de probióticos sobre a imunidade tem induzido um grande número de pesquisas, a maioria realizadas em mamíferos, nos que a estrutura dos tecidos linfóides associados ao intestino é totalmente diferente das aves, o que dificulta a transposição das informações geradas (COPPOLA \& GIL-TURNES, 2004). PANDAet al. (2003) comprovaram que a resposta imune de aves contra hemácias ovinas, não foi influenciada pelos probióticos as 20 e 40 semanas de idade, mas às 60 semanas os títulos dos animais suplementados foram significativamente superiores. GIL de los SANTOS (2004) estudou o efeito de probióticos elaborados com Saccharomyces boulardii e Bacillus cereus var. toyoii na translocação de Salmonella enteritidis em frangos de corte. Comprovou que, ao abate, a bactéria estava presente em $1,8 \%$ das amostras dos controles, mas não nos animais suplementados com os probióticos, apesar de que todos os grupos apresentaram elevados títulos de anticorpos. Comprovou, também, que os títulos de anticorpos em animais vacinados contra a Doença de Marek e as concentrações de IgA secretora em papo não diferiram entre os grupos.

Probióticos e qualidade de carcaça

Os probióticos podem afetar, também, a qualidade da carne dos animais aos quais são administrados. A suplementação com Lactobacillus reduziu os níveis de colesterol total, colesterol lipoprotéico de baixa densidade (LDL) e triglicerídeos, mas não o colesterol lipoprotéico de alta densidade (HDL), no soro sanguíneo de frangos de 21 a 42 dias de idade (KALAVATHY et al., 2003). Igualmente, PIETRAS (2001) demonstrou que L. acidophilus e Streptococcus faecium diminuíram as concentrações de proteína plasmática e os níveis de colesterol total e HDL, e que a carne dos frangos suplementados apresentava um significativo aumento no conteúdo protéico. MOHAN et al. (1996) também observaram uma redução significativa no nível de colesterol no soro sanguíneo de animais alimentados com probióticos.

SANTOSO et al. (1995) demonstraram que Bacillus subtilis na dose de $20 \mathrm{~g} \mathrm{~kg}^{-1}$ de ração, aumentou o nível de fosfolipídios no soro sanguíneo, mas reduziu a concentração de fosfolipídios na carcaça e a de triacilglicerol no fígado, carcaça e soro sanguíneo, além de diminuir a percentagem de gordura abdominal. Este parâmetro também foi avaliado por DENLI et al. (2003), que comprovaram que 
Saccharomyces cerevisiae na dieta diminuiu o peso e a porcentagem de gordura abdominal de frangos. ESTRADA et al. (2001) observaram uma tendência à redução de bactérias aeróbicas totais, coliformes e clostridios em frangos que receberam Bifidobacterium bifidum, e comprovaram uma redução no número de condenações de carcaça por celulite nos animais suplementados.

\section{CONCLUSÃO}

A avicultura industrial, que há muito tempo depende da utilização de antimicrobianos adicionados às rações fornecidas aos animais, necessita manter ou melhorar os índices de produtividade após a proibição de seu uso. Embora tenham sido relatados resultados controversos a respeito da eficácia dos probióticos, foi demonstrado que algumas espécies de probióticos, além de mudar a estrutura da microflora bacteriana do trato gastrintestinal de aves, podem prevenir infecções e melhorar a qualidade de carcaça, mantendo os mesmos índices de produtividade alcançados com a utilização de antimicrobianos, reduzindo a mortalidade, as condenações de carcaça, melhorando a conversão alimentar e o ganho de peso.

Ainda que as indústrias estejam relutantes quanto à sua incorporação nas operações industriais, alguns probióticos aparecem como uma alternativa às restrições impostas ao uso de antimicrobianos na produção animal pelos mercados consumidores mais exigentes e, assim como ocorreu na medicina humana, é muito provável que o consumo em larga escala de probióticos seja uma realidade nos próximos anos, tornando-os indispensáveis na avicultura industrial.

\section{REFERÊNCIAS BIBLIOGRÁFICAS}

ANÔNIMO, 2001. Annual report on zoonoses in Denmark 2000. Ministry of Food, Agriculture and Fisheries. Capturado em 15 out. 2003. Online. Disponível na Internet http://www.dfvf.dk/Default.asp?ID=9606

ANTUNES, P. et al. Incidence and susceptibility to antimicrobial agents of Listeria spp. and Listeria monocytogenes isolated from poultry carcasses in Porto, Portugal. Journal of Food Protection, v. 65, n. 12, p. 1888-1893, dec., 2002.

ANTUNES, P. et al. Incidence of Salmonella from poultry products and their susceptibility to antimicrobial agents. International Journal of Food Microbiology, v.82, n.2, p.97-103, 2003.

BALEVI, T. et al. Effect of dietary probiotic on performance and humoral immune response. British Poultry Science, v.42, n.4, p.456-461, 2001 .
BAÚ, A.C. et al. Prevalência de Salmonella em produtos de frangos e ovos de galinha comercializados em Pelotas, RS, Brasil. Ciência Rural, v.31, n.2, p.303-307, 2001.

CASEWELL, M. et al. The European ban on growthpromoting antibiotics and its consequences for animal and human health. Capturado em 15 nov. 2002. Online. Disponível na Internet http://www.npa-uk.net/Library/ European

CAVAZZONI, V. et al. Performance of broiler chickens supplemented with Bacillus coagulans as probiotic. British Poultry Science, v.39, n.4, p.526-529, 1998.

CHANG, Y.H. Prevalence of Salmonella spp. in poultry broilers and shell eggs in Korea. Journal of Food Protection, v.63, n.5, p.655-658, 2000.

COPPOLA, M.M.; GIL-TURNES, C. Efeito de probióticos na resposta imune. Ciência Rural, v.34, n.4, p.1297-1303, 2004.

COUNCIL OF EUROPE, 2000. Ban on antibiotics in food production. Recommendation 1446. Capturado em 15 out. 2003. Online. Disponível na Internet http://assembly.coe.int/ Documents/AdoptedText/ta00/EREC1446.HTM

COUNCIL OF THE EUROPEAN UNION. Council regulation on the authorisation of the additive avilamycin in feedingstuffs. Capturado em 15 out. 2003. Online. Disponível na Internet http://register.consilium.eu.int/ pdf/en/03/st06/st06120en03.pdf

CUEVAS, A.C. et al. El efecto del Bacillus toyoii sobre el comportamiento productivo en pollos de engorda. Veterinária México, v. 31, n. 4, 2000. Capturado em 17 out. 2003. Online. Disponível na Internet http:// www.ejournal.unam.mx/vet_mex/vol31-04/RVM31405.pdf

DALLOUL, R.A. et al. Enhanced mucosal immunity against Eimeria acervulina in broilers fed a Lactobacillus-based probiotic. Poultry Science, v.82, p.62-66, 2003

DENIS, M. et al. Campylobacter contamination in french chicken production from farm to consumers. Use of a PCR assay for detection and identification of Campylobacter jejuni and C. coli. Journal of Applied Microbiology, v.91, n.2, p.255-267, 2001.

DENLI, M. et al. Comparative effects of feeding diets containing Flavomycin, Bioteksin-L and dry yeast (Saccharomyces cerevisiae) on broiler performance. Journal of Applied Animal Research, v.23, n.2, p.139-144, 2003.

DOMINGUEZ, C. et al. Prevalence of Salmonella and Campylobacter in retail chicken meat in Spain. International Journal of Food Microbiology, v.72, n.12, p.165-168, 2002.

ESTRADA, A. et al. Administration of Bifidobacterium bifidum to chicken broilers reduces the number of carcass condemnations for cellulitis at the abattoir. Journal of Applied Poultry Research, v.10, n.4, p.329-334, 2001

FALLON, R. et al. Antimicrobial resistance of Campylobacter jejuni and Campylobacter coli isolates from broiler chickens isolated at an Irish poultry processing plant. Letters in Applied Microbiology, v.36, n.5, p.277, 2003. 
FRITTS, C.A. et al. Bacillus subtilis C-3102 (Calsporin) improves live performance and microbiological status of broiler chickens. Journal of Applied Poultry Research, v.9, n.2, p.149-155, 2000 .

FULLER, R. Probiotics in man and animals. Journal of Applied Bacteriology, v.66, n.5, p.365-378, 1989.

GIL de los SANTOS, J.R. Efeito de probióticos na translocação de Salmonella enteritidis e na eficiência alimentar de frangos de corte. 2004. 80f. Dissertação (Mestrado em Veterinária) - Programa de Pós-graduação em Veterinária, Universidade Federal de Pelotas.

GIL-SETAS, A. et al. Salmonelosis no tifoidea en un área de salud de Navarra, España. Revista Española de Salud Pública, v.76, n.1, p.49-56, 2002.

HAKKINEN, M.; SCHNEITZ, C. Efficacy of a commercial competitive exclusion product against Campylobacter jejuni. British Poultry Science, v.40, n.5, p.619-621, 1999.

HOFER, E. et al. Species and serovars of the genus Listeria isolated from different sources in Brazil from 1971 to 1997. Memórias do Instituto Oswaldo Cruz, v.95, n.5, p.615-620, 2000.

JIN, L.Z. et al. Growth performance, intestinal microbial populations, and serum cholesterol of broilers fed diets containing Lactobacillus cultures. Poultry Science, v.77, n.9, p.1259-1265, 1998a.

JIN, L.Z. et al. Effects of adherent Lactobacillus cultures on growth, weight of organs and intestinal microflora and volatile fatty acids in broilers. Animal Feed Science and Technology, v.70, n.3, p.197-209, 1998b.

KALAVATHY, R. et al. Effects of Lactobacillus cultures on growth performance, abdominal fat deposition, serum lipids and weight of organs of broiler chickens. British Poultry Science, v.44, n.1, p.139-144, 2003.

KAUR, I.P. et al. Probiotics: potential pharmaceutical applications. European Journal of Pharmaceutical Sciences, v.15, p.1-9, 2002.

LAN, P.T.N. et al. Impact of two probiotic Lactobacillus strains feeding on fecal lactobacilli and weight gains in chicken. Journal of General and Applied Microbiology, v.49, n.1, p.29-36, 2003.

LINE, J.E. et al. Yeast treatment to reduce Salmonella and Campylobacter populations associated with broiler chickens subjected to transport stress. Poultry Science, v.76, n.9, p.1227-1231, 1997.

LINE, J.E. et al. Effect of yeast-supplemented feed on Salmonella and Campylobacter populations in broilers. Poultry Science, v.77, n.3, p.405-410, 1998.

LODDI, M.M. et al. Effect of the use of probiotic and antibiotic on the performance, yield and carcass quality of broilers. Revista Brasileira de Zootecnia-Brazilian Journal of Animal Science, v.29, n.4, p.1124-1131, 2000 .

MATTAR, A.F. et al. Probiotics up-regulate MUC-2 mucin gene expression in a Caco-2 cell-culture model. Pediatric Surgery International, v.18, n.7, p.586-590, 2002.
MOHAN, B. et al. Effect of probiotic supplementation on growth, nitrogen utilization and serum cholesterol in broilers. British Poultry Science, v.37, n.2, p.395-401, 1996.

MORENO, J.E.G. et al. Adición de dos tipos de probiótico en el agua de bebida de pollos de engorde y su efecto en el comportamiento productivo, metabólico, anatomopatológico e inmunológico. Expedición Científica y Cultural, v. 8, 2002. Capturado em 17 out. 2003. Online. Disponível na Internet http:// w w w. un a d.edu.co/revis t a u a d/revis t a $08 /$ cienciasagrariasadicionde.htm

NAKAMURA, A. et al. Evaluation of Aviguard, a commercial competitive exclusion product for efficacy and after-effect on the antibody response of chicks to salmonella. Poultry Science, v.81, n.11, p.1653-1660, 2002.

NEPOMUCENO, E.S.; ANDREATTI, R.L.F. Probióticos e prebióticos na avicultura. In: II SIMPÓSIO DE SANIDADE AVÍCOLA, 2000, Santa Maria, RS. Anais... Concórdia, SC : EMBRAPA SUÍNOS E AVES, v.1, p.45-55, 2000.

OZCAN, M. et al. The effects of Enterococcus faecium Cernelle 68 (SF 68) on output properties and some haematological parameters in broilers. Medycyna Weterynaryjna, v.59, n.6, p.496-500, 2003.

PANDA, A.K. et al. Growth, carcass characteristics, immunocompetence and response to Escherichia coli of broilers fed diets with various levels of probiotic. Archiv Fur Geflugelkunde, v.64, n.4, p.152-156, 2000.

PANDA, A.K. et al. Production performance, serum/yolk cholesterol and immune competence of white leghorn layers as influenced by dietary supplementation with probiotic. Tropical Animal Health and Production, v.35, n.1, p.8594, 2003.

PASCUAL, M. et al. Lactobacillus salivarius CTC2197 prevents Salmonella enteritidis colonization in chickens. Applied and Environmental Microbiology, v.65, n.11, p.4981-4986, 1999.

PATTERSON, J.A.; BURKHOLDER, K.M. Application of prebiotics and probiotics in poultry production. Poultry Science, v.82, n.4, p.627-631, 2003.

PERESI, J.T.M. et al. Surtos de enfermidades transmitidas por alimentos causados por Salmonella enteritidis. Revista de Saúde Pública, v.32, n.5, p.477-483, 1998.

PEZZOTTI, G. et al. Occurrence and resistance to antibiotics of Campylobacter jejuni and Campylobacter coli in animals and meat in northeastern Italy. International Journal of Food Microbiology, v.82, n.3, p.281-287, 2003.

PIETRAS, M. The effect of probiotics on selected blood and meat parameters of broiler chickens. Journal of Animal and Feed Sciences, v.10, p.297-302, Supp1.2, 2001.

REVINGTON, B. Feeding poultry in the post-antibiotic era. In: MULTI-STATE POULTRY MEETING, Indiana, U.S.A. Anais... Capturado em 17 out, 2003. Online. Disponível em http://ag.ansc.purdue.edu/poultry/multistate/Multistate.pdf 
REYES, H.S.R. et al. Efectos de la aplicación de bacterias lácticas y ácido láctico en la ganancia de peso y mortalidad en pollos. Revista Científica - Facultad de Ciencias Veterinarias, Zulia, v.10, n.4, p.310-314, 2000.

SALMINEN, S. et al. Clinical applications of probiotic bacteria International Dairy Journal, v.8, p.563-572, 1998a.

SALMINEN, S. et al. Demonstration of safety of probioticsa review. International Journal of Food Microbiology, v.44, p.93-106, 1998 b

SALMINEN, S. et al. Probiotics: how should they be defined? Trends in Food Science \& Technology, v.10, p.107-110, 1999.

SANTOS, D.M.S. et al. Salmonella em carcaças de frango congeladas. Pesquisa Veterinária Brasileira, v.20, n.1, p. $39-42,2000$
SANTOSO U. et al. Effect of dried Bacillus subtilis culture on growth, body composition and hepatic lipogenic enzyme activity in female broiler chicks. British Journal of Nutrition, v.74, n.4, p.523-529, 1995.

SCHREZENMEIR, J.; DE VRESE, M. Probiotics, prebiotics and symbiotics-approaching a definition. American Journal of Clinical Nutrition, v.73, p.361S-364S, 2001.

SWANN COMMITTEE BVA and RCVS evidence to the Swann Committee. Veterinary Record, jan.25, p.91$92,1969$.

ZULKIFLI, I. et al. Growth performance and immune response of two commercial broiler strains fed diets containing Lactobacillus cultures and oxytetracycline under heat stress conditions. British Poultry Science, v.41, n.5, p.593-597, 2000 